\title{
əWind Speed Measured from Underwater Gliders Using Passive Acoustics ${ }^{\mathscr{a}}$
}

\author{
PIERRE CAUCHY \\ Centre for Ocean and Atmospheric Sciences, University of East Anglia, Norwich, and Centre for \\ Environment, Fisheries and Aquaculture Science, Lowestoft, United Kingdom \\ KAREN J. HEYWOOD \\ Centre for Ocean and Atmospheric Sciences, University of East Anglia, Norwich, United Kingdom \\ NATHAN D. MERCHANT \\ Centre for Environment, Fisheries and Aquaculture Science, Lowestoft, United Kingdom \\ BASTIEN Y. QUESTE \\ Centre for Ocean and Atmospheric Sciences, University of East Anglia, Norwich, United Kingdom \\ PIERRE TESTOR \\ CNRS-Sorbonne Universités (UPMC Université Pierre et Marie Curie, Paris 06)-CNRS-IRD-MNHN, UMR 7159, Laboratoire \\ d'Océanographie et de Climatologie (LOCEAN), L'Institut Pierre-Simon Laplace (IPSL), Observatoire Ecce Terra, Paris, France
}

(Manuscript received 7 December 2017, in final form 9 May 2018)

\begin{abstract}
Wind speed measurements are needed to understand ocean-atmosphere coupling processes and their effects on climate. Satellite observations provide sufficient spatial and temporal coverage but are lacking adequate calibration, while ship- and mooring-based observations are spatially limited and have technical shortcomings. However, wind-generated underwater noise can be used to measure wind speed, a method known as Weather Observations Through Ambient Noise (WOTAN). Here, we adapt the WOTAN technique for application to ocean gliders, enabling calibrated wind speed measurements to be combined with contemporaneous oceanographic profiles over extended spatial and temporal scales. We demonstrate the methodology in three glider surveys in the Mediterranean Sea during winter 2012/13. Wind speeds ranged from 2 to $21.5 \mathrm{~m} \mathrm{~s}^{-1}$, and the relationship to underwater ambient noise measured from the glider was quantified. A two-regime linear model is proposed, which validates a previous linear model for light winds (below $12 \mathrm{~m} \mathrm{~s}^{-1}$ ) and identifies a regime change in the noise generation mechanism at higher wind speeds. This proposed model improves on previous work by extending the validated model range to strong winds of up to $21.5 \mathrm{~m} \mathrm{~s}^{-1}$. The acquisition, data processing, and calibration steps are described. Future applications for glider-based wind speed observations and the development of a global wind speed estimation model are discussed.
\end{abstract}

D Denotes content that is immediately available upon publication as open access.

Supplemental information related to this paper is available at the Journals Online website: https://doi.org/10.1175/JTECH-D-170209.s1.

Corresponding author: Pierre Cauchy, p.cauchy@uea.ac.uk

\section{Introduction}

Quantifying air-sea fluxes is critical in understanding the weather-ocean-climate system. Numerical models need forcing by in situ measurements at an increasingly higher spatial and temporal resolution (Zhang et al. 2006). Sea

This article is licensed under a Creative Commons Attribution 4.0 license (http://creativecommons. org/licenses/by/4.0/).

DOI: 10.1175/JTECH-D-17-0209.1 
surface wind speed is a key parameter in forcing numerical models, as well as in quantifying turbulent air-sea fluxes and gas exchanges (Wanninkhof 2014).

Observations made from satellites can provide wind speed data with near-global coverage over the ice-free oceans with a spatial and temporal resolution of about $0.25^{\circ}$ and $24 \mathrm{~h}$ (e.g., QuikScat, ASCAT), respectively. However, there is a lack of calibration of in situ observations outside the tropics and away from coasts, or in high wind speed $\left(>18 \mathrm{~m} \mathrm{~s}^{-1}\right.$ ) conditions (Bourassa et al. 2010). In situ monitoring of weather conditions over the ocean is difficult to achieve. Ship-based observations are affected by airflow distortion (Moat et al. 2005) and are sparse (Kent 1998). Making observations from moored meteorological buoys in the long term (years to decades) presents difficulties, such as damage or loss caused by the roughness of the sea surface environment (storms, ice, fishing activity, vandalism, etc.). The spatial coverage offered by moored meteorological buoys and shipbased observations remains limited, as is their ability to provide observations of extreme wind events, because of sensor and platform limitations (Weller et al. 2008).

The Weather Observations Through Ambient Noise (WOTAN) technique (Vagle et al. 1990) enables monitoring of the sea surface weather conditions from underwater, away from the rough sea-air interface, with no difficulties induced by extreme weather events. This approach relies on the analysis of underwater ambient noise, generated by the excitation of the sea surface by the weather conditions. Surface-generated noise can be recorded up to at least $6 \mathrm{~km}$ deep (Barclay and Buckingham 2013). The unique characteristics of the main underwater sound sources (e.g., spectrum shape, time variability) allow wind-generated noise to be isolated and quantified (Fig. 1).

Underwater noise generated by surface weather conditions was first studied in the mid-twentieth century, because of its effect on the performance of submarine detection systems (Urick and Kuperman 1989). In the open ocean, and in the absence of sound from marine life or nearby ships, the main source contributing to underwater sound in the frequency band from $500 \mathrm{~Hz}$ to $50 \mathrm{kHz}$ is the sound produced by surface weather conditions (Black et al. 1997; Vagle et al. 1990; Wenz 1962). The action of the wind on the surface of the ocean induces air bubbles, spray, splash, and turbulence noise, which contribute to underwater ambient noise (Carey et al. 1993). These complex surface processes are influenced by multiple parameters, such as wind speed, wind duration, fetch, and marine atmospheric boundary layer (MABL) stability. In this study, we will focus on the instantaneous wind speed only, as a first-order approximation. A linear relationship between the logarithm of the surface wind speed and the

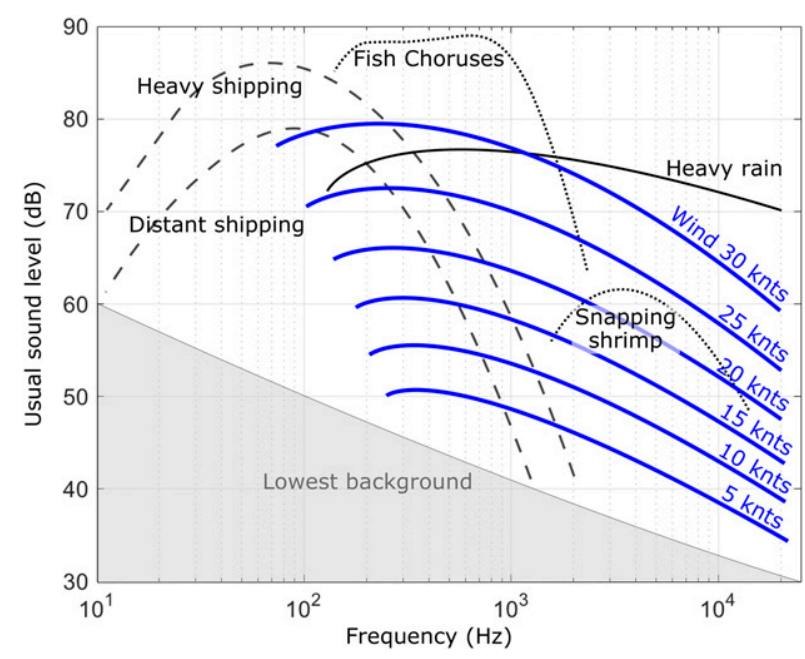

FIG. 1. Spectra of the typical contributions to underwater ambient noise in the open ocean, from anthropogenic (dashed), biotic (dotted), and abiotic (continuous) sources [adapted from Wenz (1962)]. In the absence of heavy rain events or nearby biotic activity, wind-generated noise is predominant in the $500 \mathrm{~Hz}-20 \mathrm{kHz}$ frequency range.

sound pressure level (decibels) was first reported in shallow water ( $\sim 40 \mathrm{~m})$ (Piggott 1964), and then extended to deep water $(5000 \mathrm{~m})$ in the $1-10-\mathrm{kHz}$ frequency range (Crouch and Burt 1972; Shaw et al. 1978). An empirical linear relationship between the surface wind speed and the sound pressure $(\mu \mathrm{Pa})$ was then proposed in the $4-15 \mathrm{~m} \mathrm{~s}^{-1}$ wind speed range (Vagle et al. 1990), which is now widely used (Nystuen and Ma 2002; Riser et al. 2008; Vakkayil et al. 1996).

The wind speed measured using this technique is relative to the sea surface, so it is applicable to estimation of heat and moisture fluxes and wind stress (Bourassa et al. 2010). The WOTAN technique spatially averages over an area dependent on the frequency used, the depth of the measurement, and the sound speed profile at the measurement site. At $3 \mathrm{kHz}$, it varies from $0.1 \mathrm{~km}^{2}$ for a measurement depth of $100 \mathrm{~m}$ to $10 \mathrm{~km}^{2}$ for a measurement depth of $1000 \mathrm{~m}$ (Vagle et al. 1990). For increasing frequencies, the sound absorption coefficient increases, thus the listening area decreases. This spatial scale corresponds to the scales considered in air-sea interaction studies (Bourassa et al. 2010).

The linear relationship

$$
p=b+s U
$$

between the sound pressure $p(\mu \mathrm{Pa})$ and the surface wind speed $U\left(\mathrm{~m} \mathrm{~s}^{-1}\right)$, where $b(\mu \mathrm{Pa})$ and $s\left(\mu \mathrm{Pa} \mathrm{m}^{-1} \mathrm{~s}\right)$ are respectively the offset and slope of the linear regression, is widely used in most recent studies (Nystuen and Ma 2002; Riser et al. 2008; Vakkayil et al. 1996). These studies 



FIG. 2. Model B003A Acousonde (reproduced with permission of Greeneridge Sciences, Inc.) (top) layout and (bottom) assembled with a B003-XHD external three-D-cell alkaline battery $(4.5 \mathrm{~V}, 15 \mathrm{Ah})$ housing mounted on a Slocum glider.

agree on a low wind speed limit of around $2 \mathrm{~m} \mathrm{~s}^{-1}$, below which the wind-generated sound is below the background noise level. They also agree on a high wind speed limit around $15 \mathrm{~m} \mathrm{~s}^{-1}$, above which measurements are scattered and the correlations are poor, and propose an explanation based on the hypothesis of bubble-layer attenuation of surf noise (Black et al. 1997; Farmer and Lemon 1984). It is worth noting that these previous studies contained few observations of high wind speeds.

Ocean gliders are autonomous underwater vehicles, carrying sensors to monitor the ocean. They perform long autonomous missions (several months to a year, and several thousand kilometers) and provide highresolution $(\sim 2 \mathrm{~h}, 2 \mathrm{~km})$ hydrographic profiles (Testor et al. 2010; Rudnick 2016). Glider measurements are not affected by extreme weather events. Their unique way of moving through the water column (buoyancy driven with no propellers) makes them extremely quiet and therefore very suitable for passive acoustic monitoring. Gliders also measure temperature and salinity profiles, from which sound velocity profiles can be derived. This collocated information on the acoustical properties of the water column is of considerable value for soundscape studies. Passive acoustic monitoring (PAM) sensors have been successfully deployed on ocean gliders for cetacean monitoring purposes (Baumgartner and Fratantoni 2008; Baumgartner et al. 2013; Klinck et al. 2012; Moore et al. 2007). The combination of hydrographic profiles with surface weather measurements on submesoscales (i.e., kilometer scale), tracking a weather event or monitoring a selected area for many months, would be highly valuable for air-sea interaction studies.

This paper presents a novel method for measuring surface wind speed using glider-borne underwater ambient noise measurements, from the subsurface to $1 \mathrm{~km}$ deep. We deployed gliders equipped with PAM sensors in the Mediterranean Sea during winter 2012/13 in the framework of the Deep Water formation Experiment (DEWEX) experiment (Testor et al. 2017). The gliders recorded 4 months of acoustic data, with recurring opportunities to compare our wind speed estimates with Météo-France meteorological buoys in the area. Focusing on the sound pressure level in the $3-\mathrm{kHz}$ third octave band, which shows the most dynamic response to wind speed, we estimate the surface wind speed around the glider's position $\left(0.1-10 \mathrm{~km}^{2}\right)$ throughout the $2-21.5 \mathrm{~m} \mathrm{~s}^{-1}$ wind speed range. Section 2 describes the experiment and 


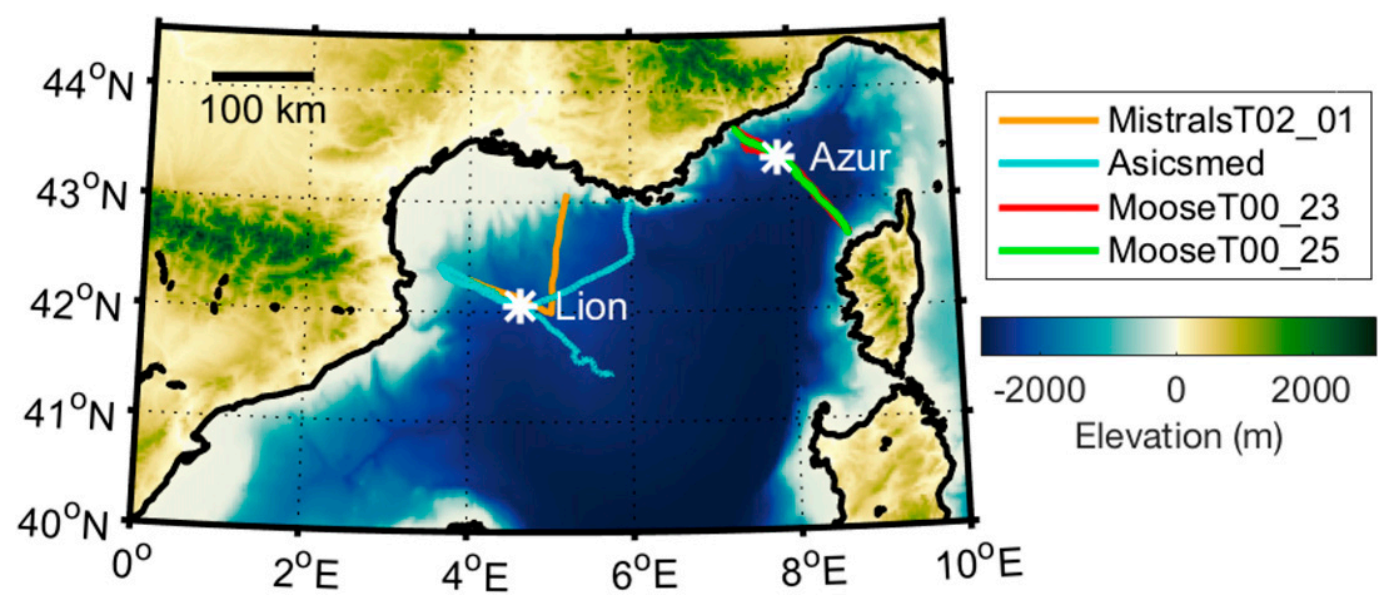

FIG. 3. Map of the Gulf of Lion (Lambert projection), tracks of the four glider missions, and location of the two Météo-France meteorological buoys, Lion and Azur.

the associated datasets. Section 3 presents the data acquisition and processing methods, and the results. Section 4 presents the wind speed derivation model and its performance. In section 5, we consider the broader application of the model to different experiments or regions, and we discuss future improvements and the contribution to wider monitoring activities.

\section{Instrumentation and field measurements}

Passive acoustic measurements were made using an Acousonde B003A-HF datalogger (Fig. 2), developed by Greeneridge Sciences, Inc. The Acousonde is a self-contained underwater acoustic recorder comprising two hydrophones, sensors for attitude, orientation, depth, and temperature, a digital recorder, and a field-replaceable battery (Burgess 2010). The core of the sensor consists of a high-frequency hydrophone (capable of sampling up to $232 \mathrm{kHz}$ ), with a sensitivity of $-204 \mathrm{~dB}$

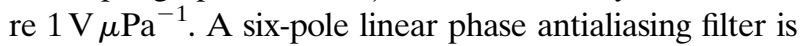
used with cutoff at $10 \mathrm{kHz}(-3 \mathrm{~dB})$ and $42 \mathrm{kHz}(-22 \mathrm{~dB})$, and a linear high-pass filter with cutoff at $10 \mathrm{kHz}(-3 \mathrm{~dB})$ (see Fig. S1 in the online supplemental material). Data are stored on a 128-GB flash memory, with a 16-bit sampling resolution. An external three-D-cell tethered battery pack allows up to $200 \mathrm{~h}$ of recording. The Acousonde operates autonomously, and has its own battery, memory, and programmed mission. Data processing is undertaken after the sensor is recovered. Initially developed to be attached to marine mammals (Cazau et al. 2017), it has also been used on ocean gliders (Nott 2015). Details of the sampling method used in this study are given in section 3 .

The platform we used in this study is the Slocum glider, developed by Teledyne Webb Research. It is driven by buoyancy changes, controlled by $500 \mathrm{~cm}^{3}$ of oil pumped into or out of a swim bladder, inducing a vertical motion in the water column, from the surface down to 1000-m depth. Fixed wings convert the vertical velocity into forward velocity, internal battery displacements enable pitch and roll management, and a moving rudder enables direction changes. This novel way of propulsion makes it a very quiet platform between the oil pumping phases that occur at the apogee and perigee of each dive ( $~ 2 \mathrm{~h}$ for $1000-\mathrm{m}$ dives). Water turbulence around the sensor induces flow noise, proportional to the glider's speed in the 5-50-Hz frequency band (Dos Santos et al. 2016; Erbe et al. 2015), with no effects regarding the windgenerated sound levels over $1 \mathrm{kHz}$. The version of the Slocum gliders we used can complete autonomous missions up to 3 months and $1000 \mathrm{~km}$ long. Along with the external PAM sensor, the gliders were equipped with integrated temperature, salinity, and pressure sensors.

The experiment took place within the Mediterranean Ocean Observing System for the Environment (MOOSE) framework, which aims to monitor the oceanographic variability of the northwestern Mediterranean Basin over a continuum of spatial and temporal scales (http:// www.moose-network.fr), and the DEWEX experiment (Testor et al. 2017). From December 2012 to May 2013, PAM-equipped gliders were deployed along the MOOSE T00 [Nice, France-Calvi (Ligurian Sea), France] and MOOSE T02 [Marseille, France-Menorca, Spain (Gulf of Lion)] glider endurance lines (Fig. 3). These lines closely pass the two Météo-France meteorological buoys Lion and Azur, defining two distinct experiment sites in which continuous in situ surface wind measurements are available, thus allowing recurring calibration and validation of the glider measurements.

These two experiment sites present different geographical characteristics, hence different spatial variability 
scales in their wind fields. The Lion buoy $\left(42.06^{\circ} \mathrm{N}\right.$, $4.64^{\circ} \mathrm{E}$ ) is in the middle of the Gulf of Lion, $100 \mathrm{~km}$ from the nearest shore, in waters $2300 \mathrm{~m}$ deep, in an open sea area affected by the mistral and tramontane winds, and away from the main shipping lanes. The Azur buoy $\left(43.38^{\circ} \mathrm{N}, 7.83^{\circ} \mathrm{E}\right)$ is $50 \mathrm{~km}$ from the shore, in waters $2300 \mathrm{~m}$ deep, in an area affected by cyclogenesis in the Gulf of Genoa (Rainaud et al. 2016), and close to the alongshore shipping lanes. Each buoy measurement is considered to represent the conditions for an area around the buoy's position, whose size depends on the spatial variability of the measured parameters and the geographical position of the buoy. To better estimate the area represented by each buoy wind speed measurement, we used output from the atmospheric model Application of Research to Operations at MesoscaleWestern Mediterranean (AROME-WMED; Nuret and Fourrie 2011) to compare the wind speed at the buoy position with the wind speed for the rest of the Gulf of Lion, for the two sites, Lion and Azur (Fig. 4). Around the Lion buoy, the correlation (0.93), root-mean-square (RMS) difference $\left(2.1 \mathrm{~m} \mathrm{~s}^{-1}\right)$, and mean difference $\left(0.2 \mathrm{~m} \mathrm{~s}^{-1}\right)$ with the wind speed at the buoy position are good within $80 \mathrm{~km}$ of the buoy, with a rapid deterioration outside. We define this as the Lion confidence area, in which we use the buoy 1-min average measurements of wind speed at $10 \mathrm{~m}$ as ground truth. Around the Azur buoy, this radius decreases to $40 \mathrm{~km}$. We defined the Azur confidence area as a $40-\mathrm{km}$ radius around the Azur buoy that provides hourly average measurements of wind speed at $10 \mathrm{~m}$, with mean correlation, RMS difference, and difference of $0.86,2.5 \mathrm{~m} \mathrm{~s}^{-1}$, and $0.2 \mathrm{~m} \mathrm{~s}^{-1}$, respectively (Fig. 4).

We undertook four PAM glider deployments around the two sites, Lion (missions Asicsmed and MistralsT02_01) and Azur (missions MooseT00_23 and MooseT00_25). These cover 138 days of data, 37 of which are within the confidence area of one of the buoys and can be used to derive a relationship between sound pressure and surface wind speed (Table 1). Multiple factors can induce differences between our measurements in the different experiments: the two buoys have different measurement sampling frequencies; shipping activity, and therefore its generated noise, is different at the two sites; and our PAM sensors have different sensitivities per experiment, because of the varying mounting position on the glider, and the difficulty of using Acousonde to produce absolute sound level measurements (Wiggins 2013). For these reasons, we decided to process each experiment separately. We merged the two Lion datasets, Asicsmed and MistralsT02_01 (referred to as Lion dataset), as both deployments used the same setup in the same area without any maintenance operations in between.
Table 1. Amount of PAM sensor data at each step of the preprocessing, for the three datasets (GB, days, and 1-min samples).

\begin{tabular}{clll}
\hline \hline \multicolumn{1}{c}{ Dataset } & \multicolumn{1}{c}{ Lion } & MooseT00_23 & MooseT00_25 \\
\hline Raw data & 45 GB & 48 GB & 33 GB \\
& 51 days & 54 days & 38 days \\
& 7371 samples & 7802 samples & 5444 samples \\
Quiet gliding & 40 days & 50 days & 14 days \\
phase & 4021 samples & 4938 samples & 1553 samples \\
Within the & 15 days & 17 days & 5 days \\
confidence area & 2081 samples & 2365 samples & 707 samples \\
\hline
\end{tabular}

\section{Acoustic data sampling and preprocessing procedures}

We designed the data acquisition protocol to evenly distribute the $200 \mathrm{~h}$ of recording time over the 3-month glider mission. The shortest sample allowed by the PAM sensor, $1 \mathrm{~min}$, is sufficient for analysis of wind-generated noise (Nystuen and Ma 2002). The PAM sensor recorded $1 \mathrm{~min}$ every $10 \mathrm{~min}$, to allow a mission duration of 80 days. The sampling rate was set at $50 \mathrm{kHz}$, constrained by the PAM sensor's onboard memory capacity. This sampling method produces $27 \mathrm{~GB}$ of data every month.

We adapted the WOTAN technique (Vagle et al. 1990). We processed each 1-min sample individually, extracting the sound level on third octave frequency bands [third octave level (TOL)], according to the standards [American National Standards Institute (ANSI) S1.11-2004] and using the software PAMGuide (Merchant et al. 2015) on 1-s-long non overlapping Hanning windows.

To focus on the wind contribution to the underwater ambient noise, any other sound sources have to be detected and removed from the dataset. The noise generated by the glider's oil pump is a loud broadband signal, lasting for several minutes. Slocum gliders generally activate their pump only during the apogee (surfacing) and perigee (bottom inflexion) phases of a dive. As we programmed only 1000 -m-deep dives, we removed data acquired during apogee (depth $<20 \mathrm{~m}$ ) and perigee (depth $>950 \mathrm{~m}$ ) to focus on the quiet gliding phase of each dive (Fig. 5). The Lion dataset contains 4021 remaining 1-min samples, the equivalent of 40 days (Table 1).

To eliminate transient sounds (e.g., clicks, whistles, and glider's motors), we assumed that wind speed is constant over a 1-min sample and kept only the minimum TOL values. We therefore condense a 1-min sample spectrogram to a single spectrum in which remains no signal of the transient sounds (Fig. 6).

The pitch of the glider varies significantly between ascending (approximately $26^{\circ}$ ) and descending (approximately $-26^{\circ}$ ) phases. To assess the effects of this variation 
(a)

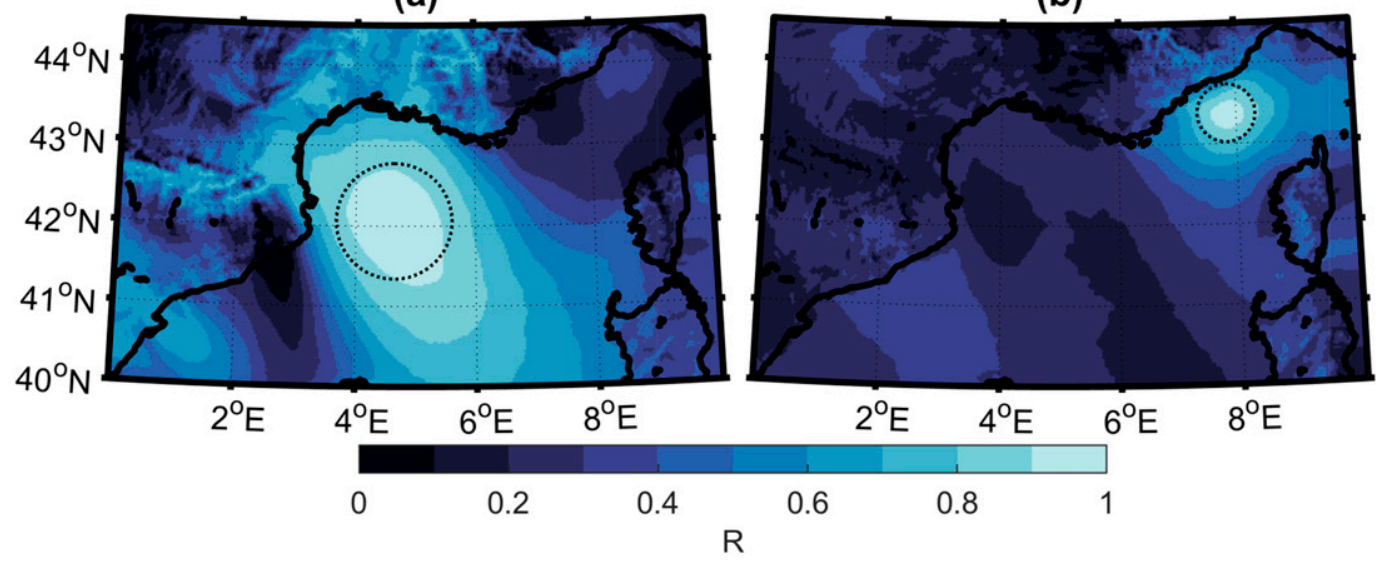

(c)

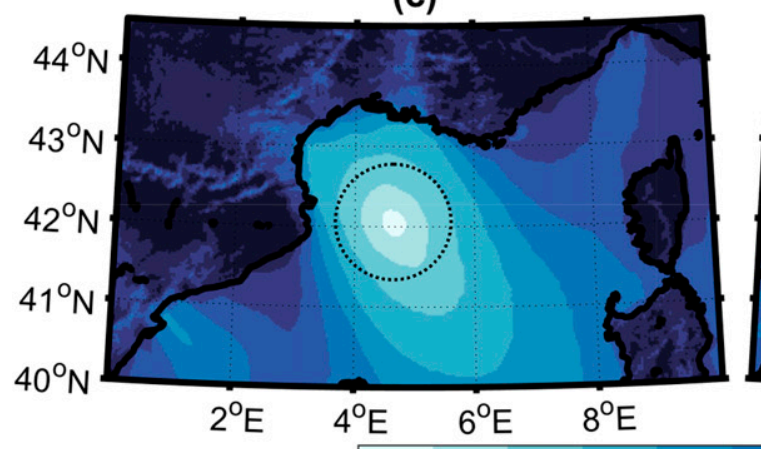

0

2

4

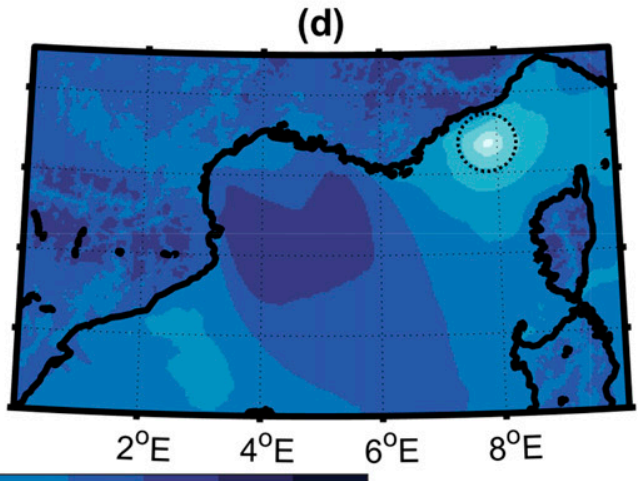

Root Mean Square difference $\left(\mathrm{m} \mathrm{s}^{-1}\right)$

(e)

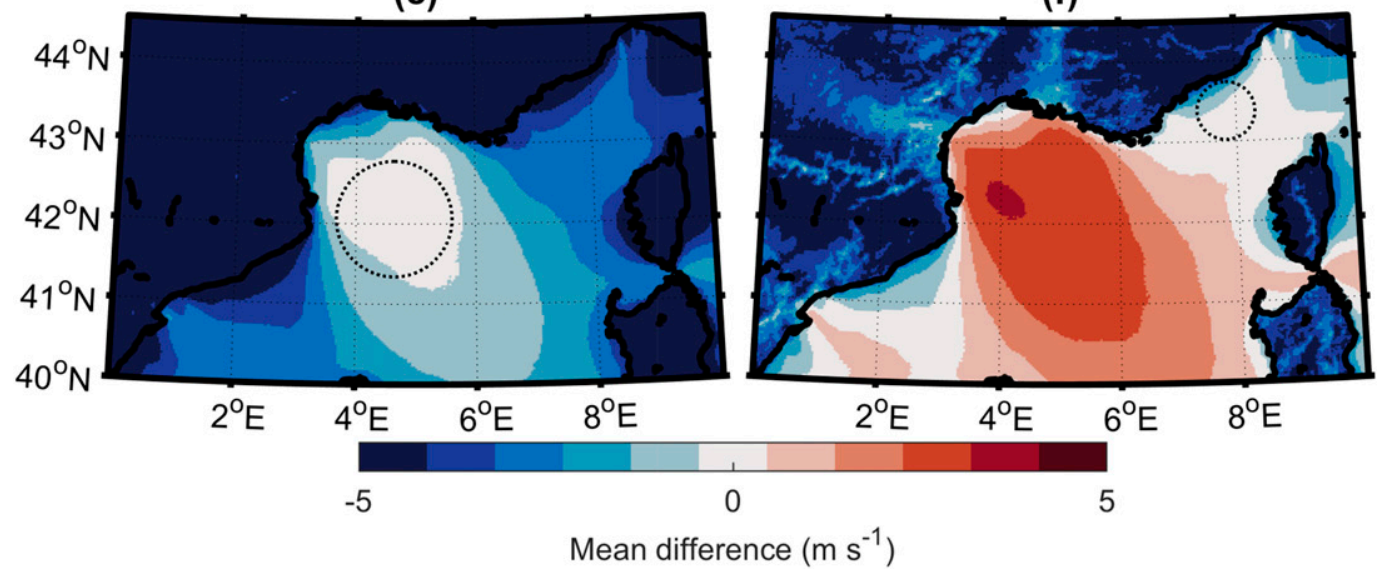

FIG. 4. Maps (Lambert projection) of the (a),(b) correlation, (c),(d) RMS difference, and (e),(f) mean difference $\left(U_{\text {buoy }}-U\right)$ of the wind speed at the sites (a),(c),(e) Lion and (b),(d),(e) Azur with the wind speed on the Gulf of Lion. The maps are computed using hourly averages of wind speed at $10 \mathrm{~m}$, from the atmospheric model AROME_WMED analysis, over the time of the glider deployments, November 2012-March 2013. The dashed circles of radius $80 \mathrm{~km}$ around the Lion buoy and $40 \mathrm{~km}$ around the Azur buoy represent the confidence areas in which we use the buoy measurements as ground truth. The mean values in the confidence areas are $\left(R=0.93, \mathrm{RMSE}=2.1 \mathrm{~m} \mathrm{~s}^{-1}\right.$, error $\left.=-0.2 \mathrm{~m} \mathrm{~s}^{-1}\right)$, and $\left(R=0.86\right.$, RMSE $=2.5 \mathrm{~m} \mathrm{~s}^{-1}$, error $\left.=-0.2 \mathrm{~m} \mathrm{~s}^{-1}\right)$ around the sites Lion and Azur, respectively. 
(a)

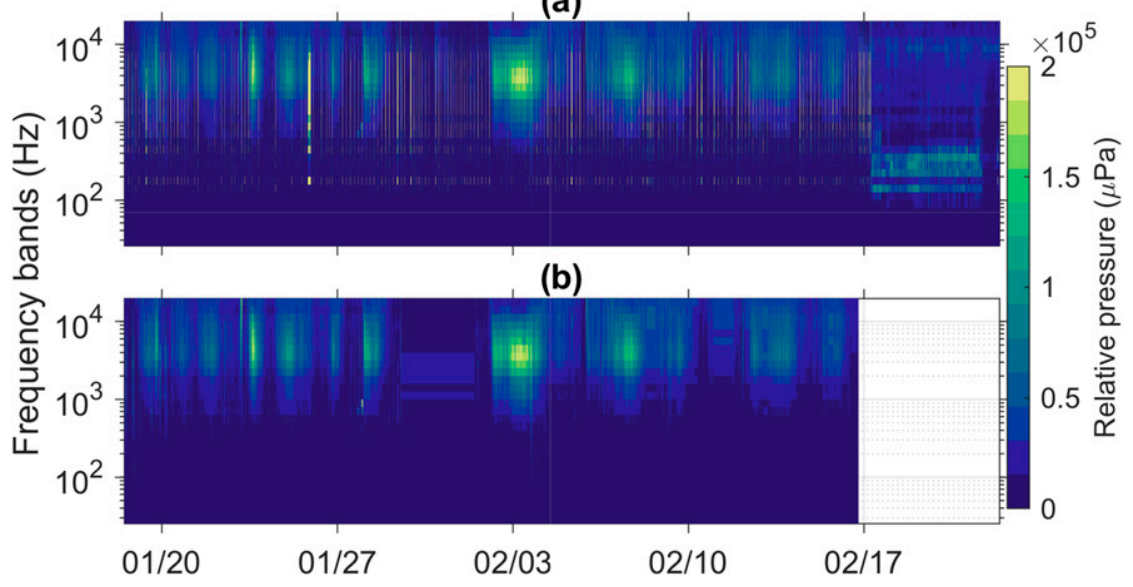

FIG. 5. (a) Raw spectrogram of the sound recorded during the Lion-Asicsmed mission and (b) after removal of the main-glider-generated noises during the apogee (depth $<20 \mathrm{~m}$ ) and perigee (depth $>950 \mathrm{~m}$ ) phases.

on the measurements, we compared the estimated wind speed during climbing and diving profiles. There is an average overestimation from the ascending profiles of $0.3 \mathrm{~m} \mathrm{~s}^{-1}$. An ANOVA test on these time series gives a $p$ value of 0.3 . Therefore, we neglected the effect of the variation of the pitch in this study.

The glider profiling behavior implies significant variations in the depth of the measurements, which affect the received sound level. The effects of refraction, attenuation, spreading loss, and directionality of the sound sources are accounted for, for each depth and frequency, depending on the sound attenuation and velocity profile (Vagle et al. 1990). Therefore, $\operatorname{TOL}(h, f)$, measured at depth $h$ and frequency $f$, can be corrected to an equivalent $\operatorname{TOL}_{0}(f)$ at the surface:

$$
\operatorname{TOL}_{0}(f)=\operatorname{TOL}(h, f)+\beta(h, f)
$$

where $\beta(h, f)=-10 \log \left(2 \int_{0}^{\infty} \frac{r \sin ^{2} \theta_{h, f} e^{-\alpha l_{h, f}}}{l_{h, f}^{2}} d r\right)$,

where $r$ is the horizontal distance from the source to the point directly above a hydrophone at $h ; l$ is the pathlength from the source to the receiver, including refraction effects; $\theta$ is the angle between the surface and the path to the receiver; $\alpha$ is the frequency-dependent attenuation coefficient for bubble-free water. For each deployment, we calculated the $\beta$ profile using the average sound velocity profile, and attenuation, obtained from the glider's temperature and salinity measurements. The average sound velocity and $\beta$ profiles are shown in Fig. S2 in the online supplement.

The applied correction for a depth of $1000 \mathrm{~m}$ is $1.3 \mathrm{~dB}$, which means that the received sound pressure $(\mu \mathrm{Pa})$ is $14 \%$ lower that the sound pressure at the surface.

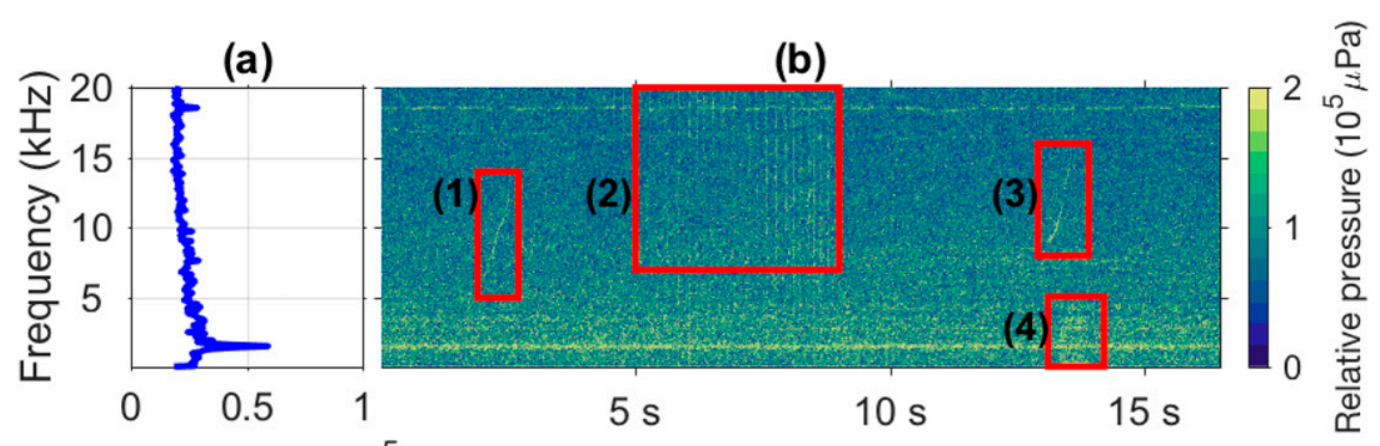

Relative pressure $\left(10^{5} \mu \mathrm{Pa}\right)$

FIG. 6. (b) Spectrogram with examples of transient noises, such as 2: biological echolocation clicks, 1 and 3 : whistles, and 4: glider's fin movement noise. (a) The associated extracted minimum spectrum shows no remaining signal of any of the identified transient sounds. The Acousonde self noise, at 2 and $18 \mathrm{kHz}$, is not removed but the affected frequencies are not used in our analysis. 
TABLE 2. Depth, frequency, and wind speed ranges of previous studies.

\begin{tabular}{lccc}
\hline \multicolumn{1}{c}{ Reference } & Depth $(\mathrm{m})$ & Frequency range & Wind speed range $\left(\mathrm{m} \mathrm{s}^{-1}\right)$ \\
\hline Piggott (1964) & 40 & $8.4 \mathrm{~Hz}-3.1 \mathrm{kHz}$ & $1-20$ \\
Wenz (1962) & & $500 \mathrm{~Hz}-5 \mathrm{kHz}$ & $1.2-20$ \\
Crouch and Burt (1972) & $800-5000$ & $10 \mathrm{~Hz}-3 \mathrm{kHz}$ & $2.5-25$ \\
Shaw et al. (1978) & 5000 & $1-10 \mathrm{kHz}$ & $2.5-12.5$ \\
Vagle et al. (1990) & $100-300$ & $3-25 \mathrm{kHz}$ & $4-15$ \\
Vakkayil et al. (1996) & $500-2600$ & $3-25 \mathrm{kHz}$ & $4-16$ \\
Black et al. (1997) & $1.8-46$ & $10-30 \mathrm{kHz}$ & $1.3-13.9$ \\
Nystuen and Ma (2002) & 38 & $100 \mathrm{~Hz}-50 \mathrm{kHz}$ & $2-12$ \\
Riser et al. (2008) & 600 & $8 \mathrm{kHz}$ & $2.3-10$ \\
\hline
\end{tabular}

The associated wind speed estimation correction varies from 0 to $2.5 \mathrm{~m} \mathrm{~s}^{-1}$ with the sound speed in the $0-25 \mathrm{~m} \mathrm{~s}^{-1}$ range. The nonlinearity observed at $9-10 \mathrm{~m} \mathrm{~s}^{-1}$ is due to the regime change. Because of the change of the derivation slope, a similar sound pressure correction will lead to a wind speed correction divided by 4 in the high wind speed regime than in the low wind speed regime.

\section{Wind speed derivation}

\section{a. Wind speed derivation model}

Previous studies (Lemon et al. 1984; Nystuen and Ma 2002; Vagle et al. 1990; Vakkayil et al. 1996) were conducted on wind speeds limited to the $3-15 \mathrm{~m} \mathrm{~s}^{-1}$ range (Table 2). These studies found a linear relationship [(1)] between sound pressure at $8 \mathrm{kHz}\left(p_{8 \mathrm{kHz}}, \mu \mathrm{Pa}\right)$ and $10-\mathrm{m}$ wind speed $\left(U_{10}, \mathrm{~m} \mathrm{~s}^{-1}\right)$. They discussed limitations at high wind speeds (Vagle et al. 1990).
In this study, we use

$$
p_{f_{c}}=10^{\frac{\mathrm{TOL}_{0}\left(f_{c}\right)}{20}}-p_{\text {min }}\left(f_{c}\right),
$$

where $p_{f_{c}}$ is the sound pressure for the third octave band of central frequency $f_{c}$, relative to the minimal pressure $p_{\min }\left(f_{c}\right)$ observed on the deployment. The correlation between $p_{f_{c}}$ measured by the glider and $U_{10}$ measured by the buoy depends on $f_{c}$. The best correlations are in the $2-10-\mathrm{kHz}$ frequency band, where the wind-generated sound is predominant (Fig. 7). The poor correlations in frequency bands below $1 \mathrm{kHz}$ is due to the predominance of non-wind-dependent sound sources (e.g., distant shipping). The poor correlations in frequency bands above $10 \mathrm{kHz}$ can be explained by the attenuation of sound in the high-frequency bands observed during high wind speed events $\left(>15 \mathrm{~m} \mathrm{~s}^{-1}\right)$ (Fig. 7). We chose to use the relative pressure in the $3-\mathrm{kHz}$ third octave band, which shows the most dynamic response (a)

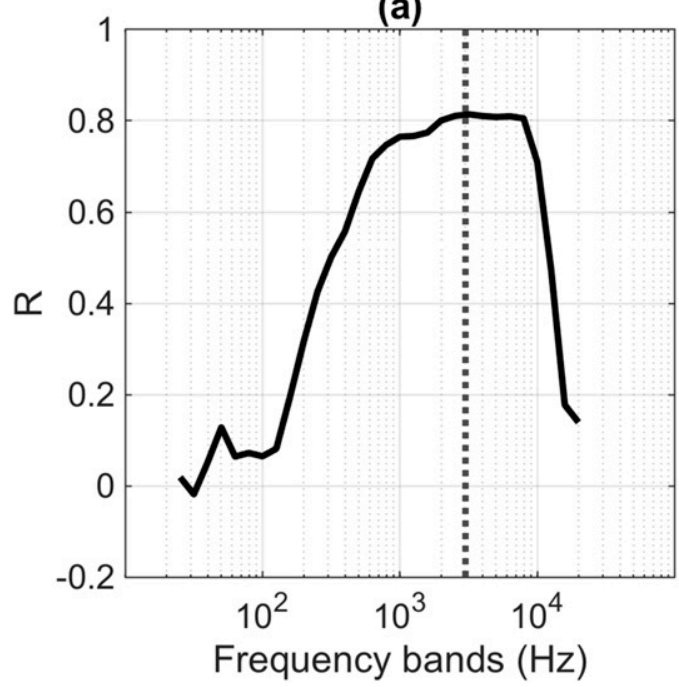

(b)

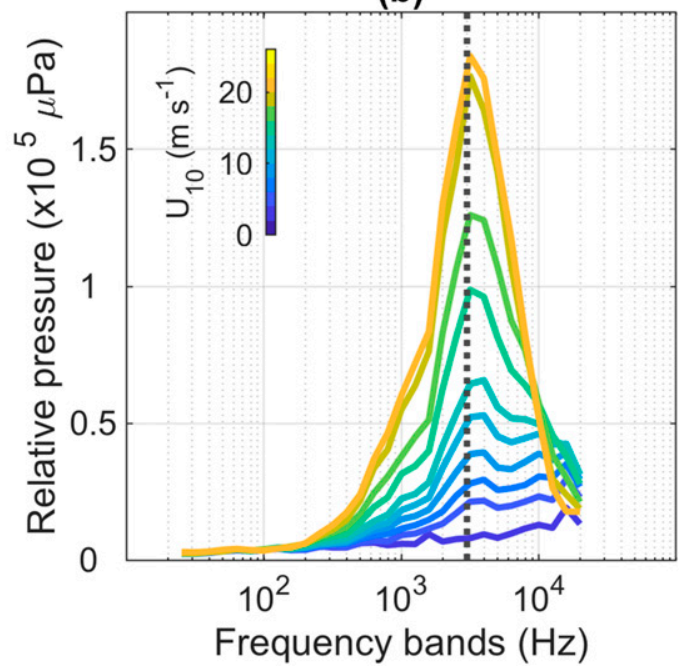

FIG. 7. (a) Correlation of the surface wind speed measurements at the Lion buoy $\left(U_{10}\right)$ with the relative pressure in third octave frequency bands recorded by the glider within $80 \mathrm{~km}$ from the site Lion. (b) Relative pressure spectrum for each $2 \mathrm{~m} \mathrm{~s}^{-1}$ wind speed bin. The black dotted line marks the $3-\mathrm{kHz}$ frequency band. 
Table 3. Distribution of buoy wind speed measurements in each $2 \mathrm{~m} \mathrm{~s}^{-1}$ wind speed bin for the Lion dataset.

\begin{tabular}{ccc}
\hline \hline$U_{10}\left(\mathrm{~m} \mathrm{~s}^{-1}\right)$ & No. of $1-$ min samples & No. of profiles \\
\hline $2-4$ & 105 & 20 \\
$4-6$ & 90 & 15 \\
$6-8$ & 120 & 17 \\
$8-10$ & 197 & 20 \\
$10-12$ & 317 & 39 \\
$12-14$ & 257 & 36 \\
$14-16$ & 147 & 16 \\
$16-18$ & 93 & 9 \\
$18-20$ & 52 & 7 \\
$20-22$ & 12 & 0 \\
$22-24$ & 0 & 0 \\
\hline
\end{tabular}

to wind speed and shows no attenuation effect during high wind speed events (Fig. 7). Similar results are obtained if other frequency bands (within 2-10-kHz range) are used.

To train our wind speed derivation model, we consider the median values of the acoustic parameter and the measured wind speed over each glider profile. As a result, contaminating sounds of duration of several 1-min samples (e.g., nearby ship) will be filtered out, and the time and length scales are the usual glider profiling scales $(\sim 2 \mathrm{~h}, 2 \mathrm{~km}$ for a 1000-m vertical profile). The number of observations is unevenly distributed over the wind speed range (Table 3). Therefore, to give an equal weight to each wind speed during the regressions between $p_{f_{c}}$ and $U_{10}$, we calculated the median sound pressure in each $2 \mathrm{~m} \mathrm{~s}^{-1}$ wind speed bin.

During our experiment, we observed several high wind speed events of $6-48 \mathrm{~h}$ of wind speed above $15 \mathrm{~m} \mathrm{~s}^{-1}$, with the glider in the confidence area around the buoy. Our dataset covers a broader wind range $\left(2-21.5 \mathrm{~m} \mathrm{~s}^{-1}\right)$ than previous studies, allowing us to investigate the relationship between $p_{f_{c}}$ and $U_{10}$ for wind speed regimes above $15 \mathrm{~m} \mathrm{~s}^{-1}$. To assess the validity of the historical single linear model [(1)] for our observations, we fitted a linear model, of parameters $b_{\text {single }}$ and $s_{\text {single }}$ (Table 4 ), to the wind speed range below $15 \mathrm{~m} \mathrm{~s}^{-1}$, simulating the wind speed range of the previous studies. Its coefficient of determination $R^{2}=0.86$ indicates a good fit for the $2-15 \mathrm{~m} \mathrm{~s}^{-1}$ range. We extrapolated this to the high wind speed range and tested it against the data available in the Lion dataset, revealing a tendency of the single linear model to overestimate wind speed in the higher wind speed range (15-21.5 $\mathrm{m} \mathrm{s}^{-1}$ ) (Fig. 8).

To improve the agreement at high wind speed we investigated the hypothesis of two distinct sound production regimes, related to the physical processes of wind-generated underwater noise (bubbles, spray, and splash). Whitecaps can be observed on sea surface images at wind speeds as low as $3.7 \mathrm{~m} \mathrm{~s}^{-1}$ (Callaghan et al. 2008), with this threshold varying with air and sea temperature (Monahan and O'Muircheartaigh 1986). Previous studies using ambient noise show a low wind speed detection threshold at $1.5-4 \mathrm{~m} \mathrm{~s}^{-1}$ (Table 2). A wind speed threshold in the range of $9-11 \mathrm{~m} \mathrm{~s}^{-1}$ is commonly used in the description of physical sea surface processes, such as the generation of spume drops, torn off wave crests by high winds (Monahan et al. 1983; Monahan et al. 2017), spray generation function (Large and Pond 1981), and drag coefficient (Foreman and Emeis 2010). As these processes all impact wind noise production, it is likely we will observe regime change in the underwater noise production at wind speeds above this threshold. We therefore defined a low wind speed range $\left(U_{10}<\right.$ $\left.11 \mathrm{~m} \mathrm{~s}^{-1}\right)$, where whitecaps are responsible only for the sound production, and a high wind speed range $\left(U_{10}>\right.$ $\left.9 \mathrm{~m} \mathrm{~s}^{-1}\right)$, where additional physical processes contribute to the sound production. We fitted two linear regressions for low wind speed parameters $b_{\text {low }}$ and $s_{\text {low }}$, and for high wind speed parameters $b_{\text {high }}$ and $s_{\text {high }}$ (Table 4). The low wind speed model is very close to the single linear model, despite being fitted on a dataset of narrower wind speed range. The two-regime linear model allows a good description of the observations for the complete measured wind speed range (Fig. 8). As an alternative to the two-regime linear model, we investigated the possibility of fitting a power-law $\left(p=a+U^{b}\right)$ relation. We obtained good results with the quadratic model$p=459.6 U^{2}$-but with a tendency to overestimate low wind speeds. We elected to use a two-regime model instead, as the fit was better and can be explained by a change in physical processes at elevated wind speeds.

The physical processes explaining the regime change appear in a continuous and smooth way, around a wind speed limit that is believed to depend on multiple

TABLE 4. Parameters of the wind speed derivation linear models of type $p=b+s U[(1)]$ for the Lion dataset.

\begin{tabular}{ccc}
\hline & Single linear model & Two-regime linear model \\
\hline Low wind speed $U_{10}<11 \mathrm{~m} \mathrm{~s}^{-1}$ & $b_{\text {single }}=-1.0 \times 10^{4}(\mu \mathrm{Pa})$ & $b_{\text {low }}=-0.2 \times 10^{4}(\mu \mathrm{Pa})$ \\
& $s_{\text {single }}=0.6 \times 10^{4}\left(\mu \mathrm{Pa} \mathrm{m}{ }^{-1} \mathrm{~s}\right)$ & $s_{\text {low }}=0.4 \times 10^{4}\left(\mu \mathrm{Pa} \mathrm{m} \mathrm{m}^{-1} \mathrm{~s}\right)$ \\
$R^{2}=0.88$ & $R_{\text {high }}=-12.5 \times 10^{4}(\mu \mathrm{Pa})$ \\
High wind speed $U_{10}>9 \mathrm{~m} \mathrm{~s}^{-1}$ & $R^{2}=0.86$ & $s_{\text {high }}=1.6 \times 10^{4}\left(\mu \mathrm{Pa} \mathrm{m} \mathrm{m}^{-1} \mathrm{~s}\right)$ \\
$R^{2}=0.95$ \\
\hline
\end{tabular}


(a)

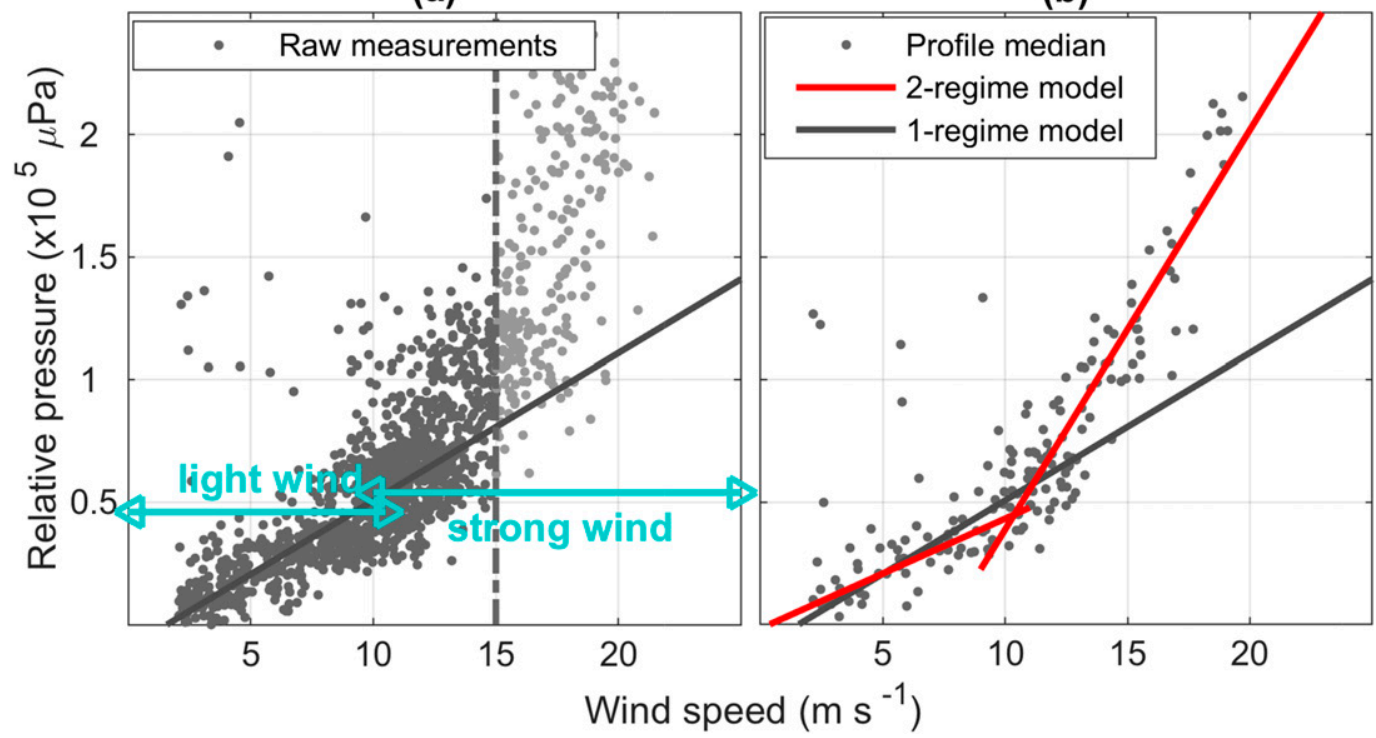

FIG. 8. (a) Variation of relative pressure at $3 \mathrm{kHz}$ with surface wind speed. The historical single linear model [(1); dark line] is obtained by regression on the wind speed data below $15 \mathrm{~m} \mathrm{~s}^{-1}$. The two wind speed regimes considered in this study are marked by blue arrows. (b) The two-regime linear model (red line) is obtained by regression on the median values in $2 \mathrm{~m} \mathrm{~s}^{-1}$ wind speed bins of the median pressure for each glider profile for the low wind speed and high wind speed subsets. parameters (sea state, current, fetch, temperature,...). To better describe this smooth transition between two different linear relationships on both sides of an undetermined joint point, we can use a hyperbola as a transition model (Watts and Bacon 1974). Therefore, we estimate $U_{3 \mathrm{kHz}}$, the wind speed derived from the sound pressure $p_{3 \mathrm{kHz}}$, as

$$
\begin{aligned}
U_{3 \mathrm{kHz}}= & U_{\text {lim }}+\frac{s_{\text {low }} \times s_{\text {high }}}{2\left(s_{\text {low }}+s_{\text {high }}\right)}\left(p_{3 \mathrm{kHz}}-p_{\text {lim }}\right) \\
& +\frac{s_{\text {high }} \times s_{\text {low }}}{2\left(s_{\text {high }}-s_{\text {low }}\right)} \sqrt{\left(p_{3 \mathrm{kHz}}-p_{\text {lim }}\right)^{2}+\frac{\partial^{2}}{4}},
\end{aligned}
$$

where $\partial=10000$ is the radius of curvature at the joint point $\left(p_{\lim }=4.5 \times 10^{4} \mu \mathrm{Pa} ; U_{\lim }=10.4 \mathrm{~m} \mathrm{~s}^{-1}\right)$ between the low $\left(s_{\text {low }}, b_{\text {low }}\right)$ and high $\left(s_{\text {high }}, b_{\text {high }}\right)$ wind speed linear models.

\section{b. Performance of the wind speed derivation model}

Prior to the estimation of the performance of the wind speed derivation model, we detected and removed some data points from the analysis that we suspected to be corrupted by an anemometer failure. They all occur during the 23-28 January 2013 period, during which the buoy measurements are sparse, and disagree with both the glider estimation and the model output (Figs. 9, 11). A comparison between the wind speed derived from the sound pressure using (5), $U_{3 \mathrm{kHz}}$, and surface wind speed measured by the buoy, $U_{10}$, shows a good agreement for the $2-20 \mathrm{~m} \mathrm{~s}^{-1}$ range. The root-mean-square of the error $\left(U_{10}-U_{3 \mathrm{kHz}}\right)$ between the estimation and the

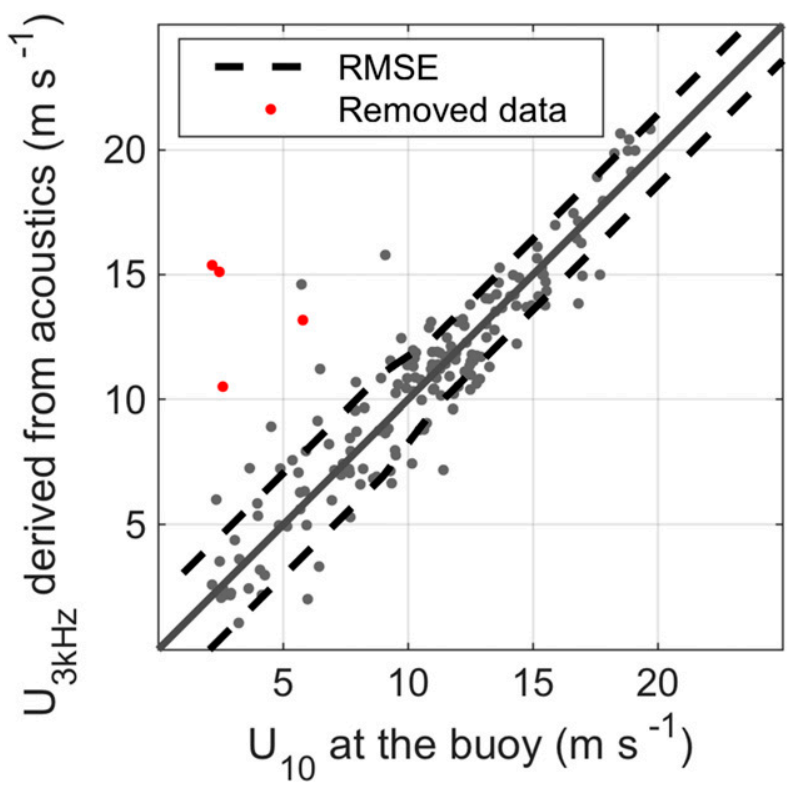

FIG. 9. Wind speed $U_{10}$ measured at the buoy vs $U_{3 \mathrm{kHz}}$ derived from acoustic measurements using the two-regime linear model with hyperbolic transition [(3)]. The RMSE is calculated on the low and high wind speed regimes. Corrupted data points, excluded from the analysis, are shown in red. 


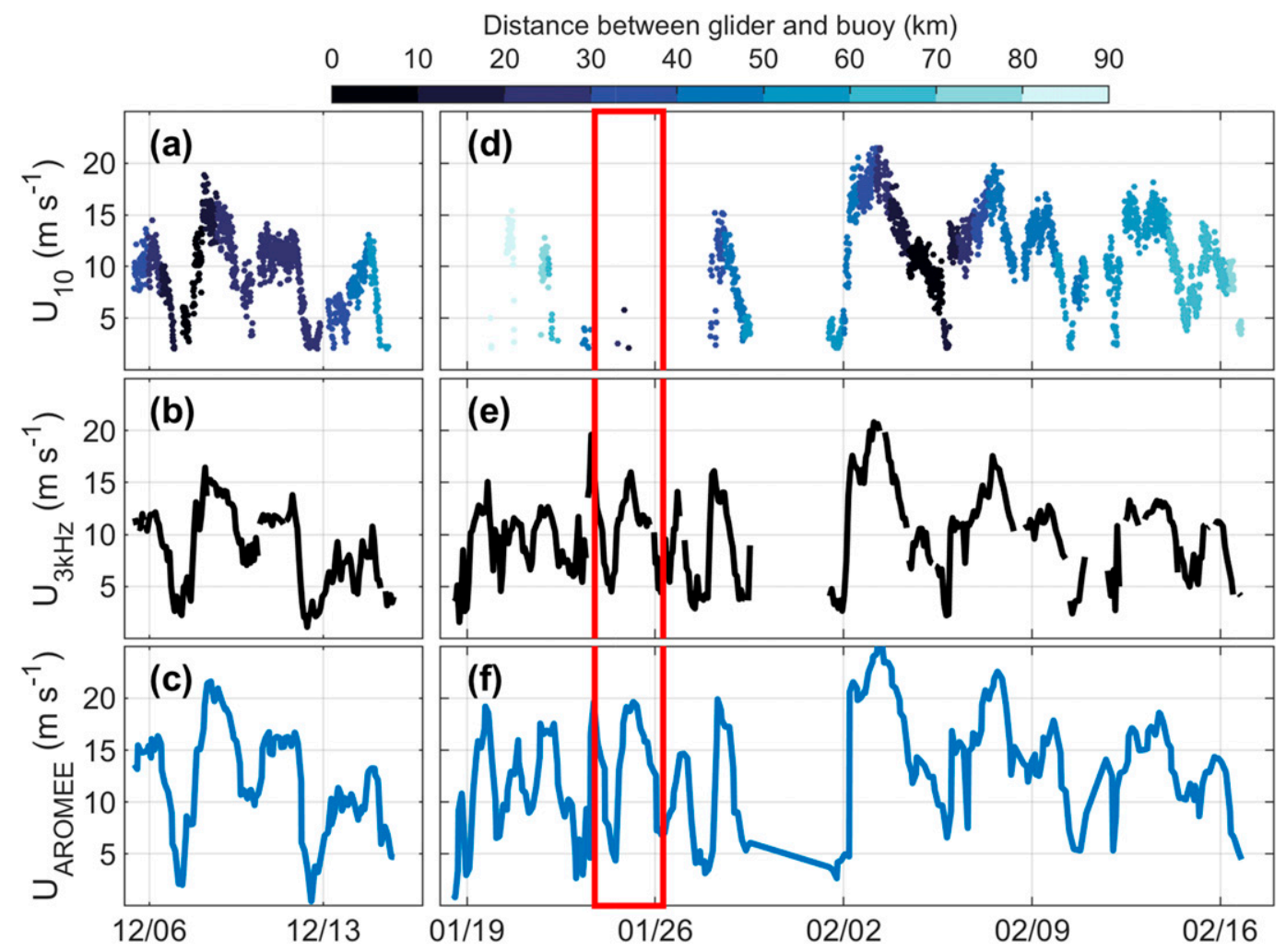

FIG. 10. Wind speed (a),(d) $U_{10}$ measured by the buoy colored by distance to the glider position, (b), (e) $U_{3 \mathrm{kHz}}$ derived from the glider acoustic measurements, and (c),(f) $U_{\mathrm{AROME}}$ from AROME_WMED model at the glider position. The data displayed are from the (a)-(c) MistralsT02_01 and (d)-(f) Asicsmed experiments that were merged into the Lion dataset. The red box shows the period where the measurements from the buoy have been discarded.

observation is 2 and $1.4 \mathrm{~m} \mathrm{~s}^{-1}$ for the low and high wind speed regimes, respectively (Fig. 9).

Because the glider traveled repeatedly toward and away from the buoy, the wind speed derivation model, calibrated against $U_{10}$ using the data collected within the buoy's confidence area, can be used when the glider is away from the buoy, extending the spatial coverage of the wind speed measurements. The time series of $U_{10}$ measured at the buoy position, $U_{3 \mathrm{kHz}}$ derived from the glider measurements, and $U_{\mathrm{AROME}}$ from the AROME_WMED model output collocated with the glider position show a good fit between $U_{3 \mathrm{kHz}}$ and $U_{\mathrm{AROME}}$ when the glider is away from the buoy confidence area (light blue color coding) and when the buoy's anemometer failed to provide data (Fig. 10).

\section{Application to other glider campaigns and implications}

The same technique was applied to the MooseT00_23 and Moose T00_25 campaigns, around the Azur meteorological buoy. For the MooseT00_23 experiment, the wind speed $U_{3 \mathrm{kHz}}$ derived using the associated hyperbolic transition model [(3)] fits $U_{10}$ measured by the buoy throughout the $2-20 \mathrm{~m} \mathrm{~s}^{-1}$ wind speed range, with a root-mean-square error of about $2.2 \mathrm{~m} \mathrm{~s}^{-1}$ in the low wind speed regime and $1.6 \mathrm{~m} \mathrm{~s}^{-1}$ in the high wind speed regime (Fig. 11). This long experiment (7 weeks), with eight occurrences of the glider surveying the Azur buoy area, illustrates the opportunity of repeated calibrations using the buoy measurements to estimate the surface wind speed along the glider path (Fig. 11).

For the MooseT00_25 experiment, the wind speed $U_{3 \mathrm{kHz}}$ derived using the associated hyperbolic transition model [(3)] fits $U_{10}$ measured by the buoy throughout the $2-17 \mathrm{~m} \mathrm{~s}^{-1}$ wind speed range, with a root-mean-square error of about $1.6 \mathrm{~m} \mathrm{~s}^{-1}$ (Fig. 12). The poor results in the $16-18 \mathrm{~m} \mathrm{~s}^{-1}$ wind speed bin can be explained by the low amount of data (six dives), all of which were recorded during one single event on 1 April. The buoy measurements during this event show a 6-h-long plateau at $17.0 \mathrm{~m} \mathrm{~s}^{-1} \mathrm{ex}-$ actly that could suggest an anemometer failure (Fig. 12).

The noticeable differences in the absolute values of the parameters (Table 5) can be explained by differences 
(a)



(b)

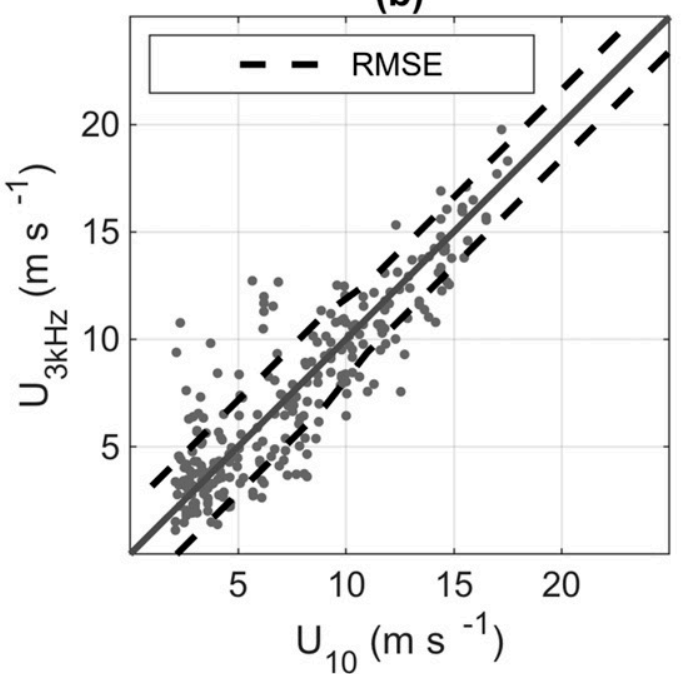

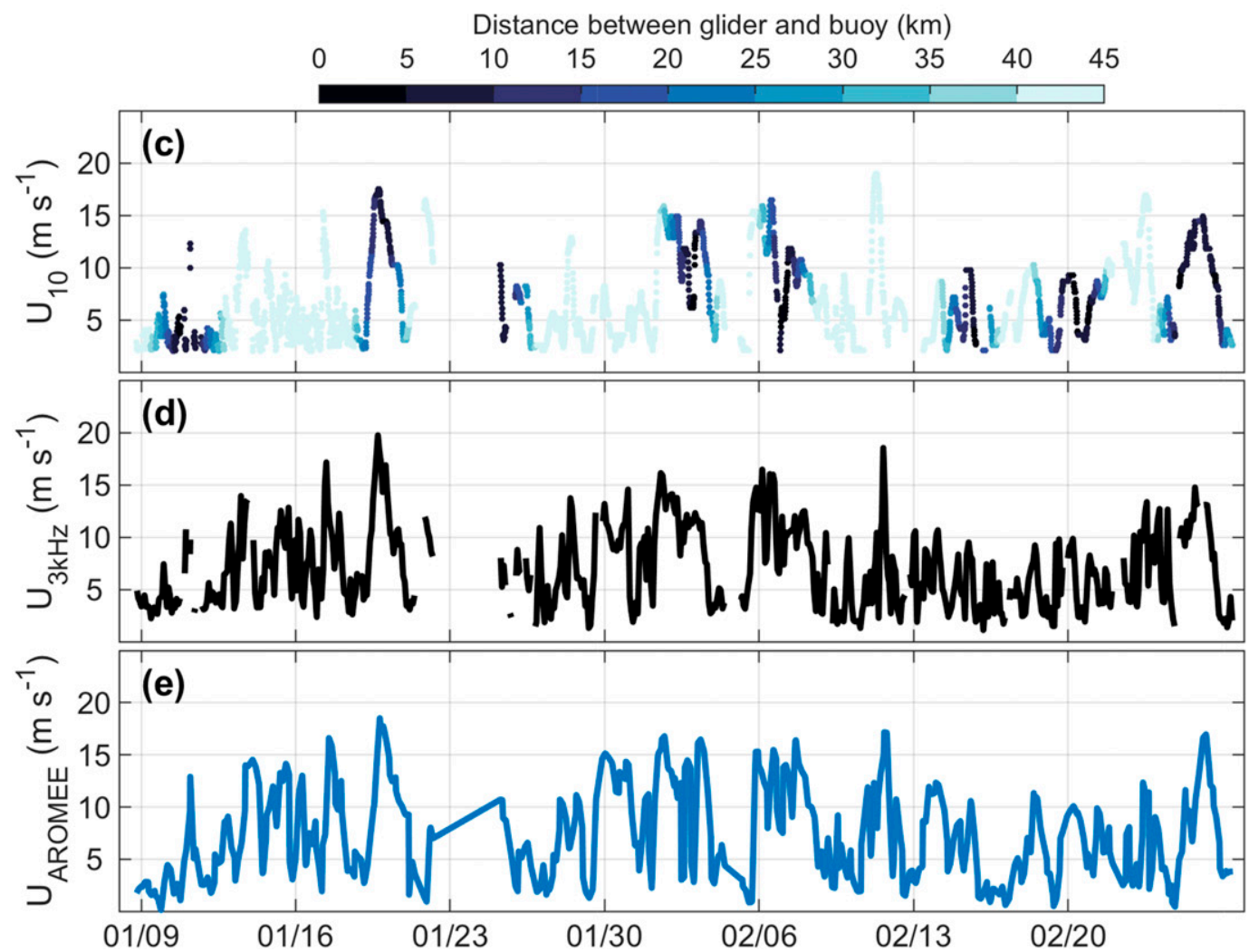

FIG. 11. (a) Two-regime linear model relationship between $p_{3 \mathrm{kHz}}$ and $U_{10}$; (b) comparison between measured $U_{10}$ and estimated $U_{3 \mathrm{kHz}}$; and time series of (c) $U_{10}$, (d) $U_{3 \mathrm{kHz}}$, and (e) $U_{\mathrm{AROME}}$ for the Azur MooseT00_23 experiment.

between the two Acousonde sensors used, and by the unavoidable variation in sound level with the orientation of the recorder in each deployment. The internal layout of the Acousonde makes it asymmetrical, with the electronic board likely to affect the measurements of the sounds coming from one side. Its cylindrical shape makes it difficult to accurately position the electronic board between the transducer and the glider's hull. This interdeployment sensitivity variability is believed to be responsible for the quantitative differences between our three experiments. Despite this variability in absolute sound level, these results show that once calibrated with 
(a)

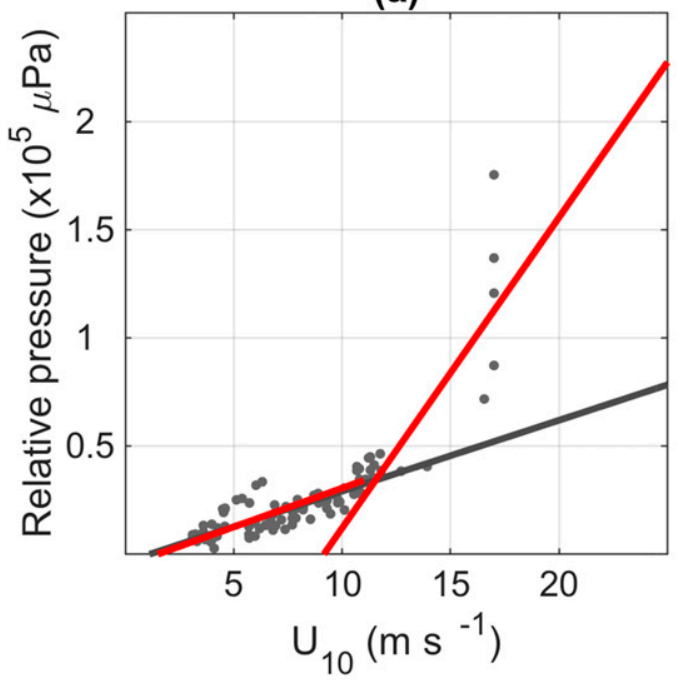

(b)

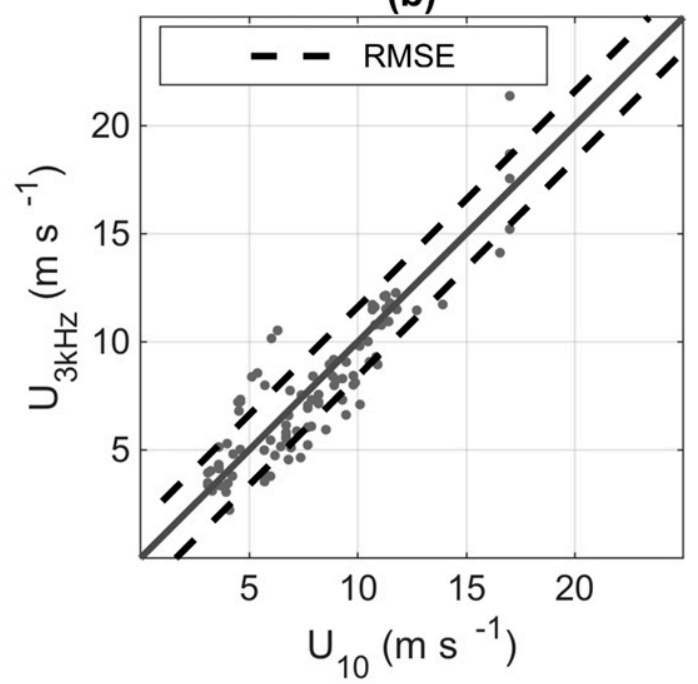

Distance between glider and buoy $(\mathrm{km})$

$\begin{array}{llllllllll}0 & 5 & 10 & 15 & 20 & 25 & 30 & 35 & 40 & 45\end{array}$

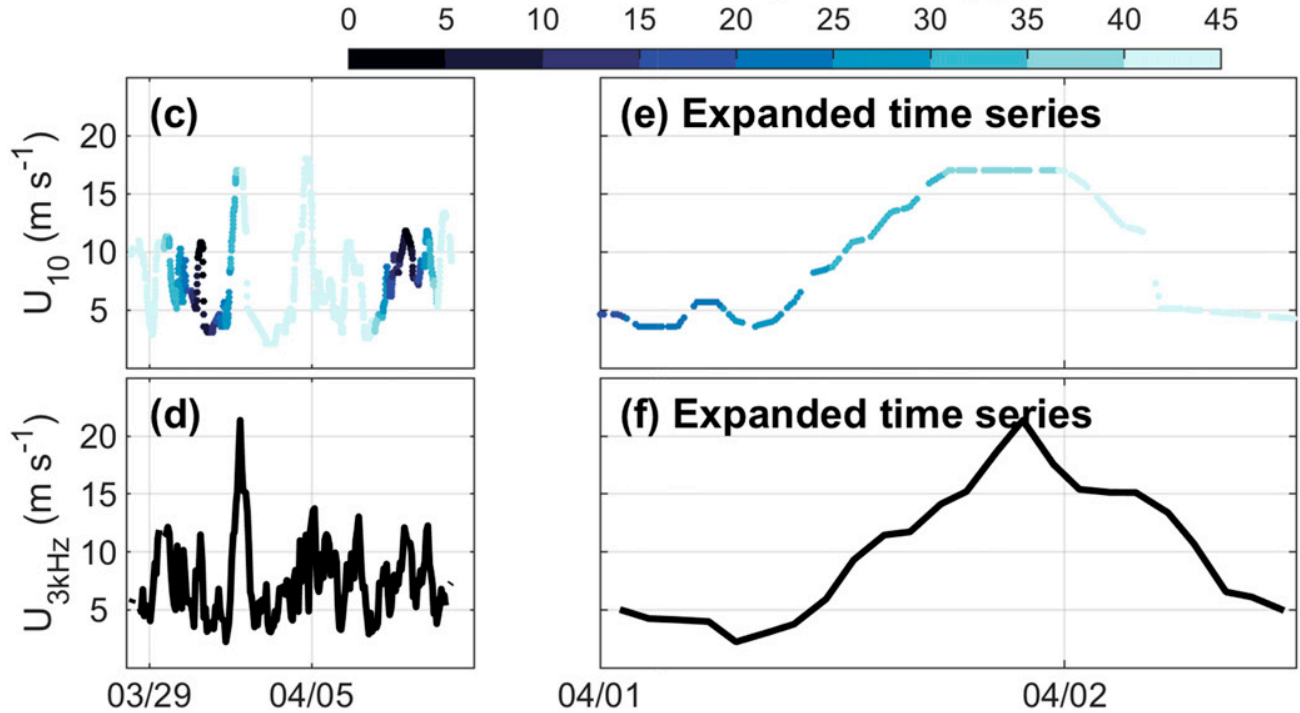

FIG. 12. (a) Two-regime linear model relationship between $p_{3 \mathrm{kHz}}$ and $U_{10}$; (b) comparison between $U_{10}$ and $U_{3 \mathrm{kHz}}$; and time series of (c) $U_{10}$ and (d) $U_{3 \mathrm{kHz}}$ for the Azur MooseT00_25 experiment. (e),(f) Expanded time series for $1 \mathrm{Apr}$ reveal a dubious $U_{10}$ plateau. No output from the AROME_WMED model are available for this experiment, which took place after the end of the Hydrological Cycle in the Mediterranean Experiment (HyMeX) exercise.

buoy data, a relative sound level can be used and produces consistent results.

The recent availability of PAM sensors integrated into ocean gliders should reduce this interdeployment sensitivity variability. Being able to calibrate the whole PAM/ glider system in situ once, knowing that the sensitivity will be the same for each following deployment, will allow using the PAM glider for wind speed estimation in areas where in situ calibration data are not available.

The method we propose here is based on relative sound pressure levels. Building a similar model using absolute sound pressure levels would improve the method, since it would negate the need for a specific in situ calibration, although the consistency of these absolute measurements (e.g., for different sensor orientations) would need to be tested.

\section{Discussion}

The adaptation of the WOTAN technique (Vagle et al. 1990) to recordings from ocean gliders provides wind speed measurements with long endurance, large spatial 
TABLE 5. Parameters of the wind speed derivation two-regime linear models for the Lion, MooseT00_23, and MooseT00_25 datasets.

\begin{tabular}{cccc}
\hline \hline & Lion & MooseT00_23 & MooseT00_25 \\
\hline For $U_{10}<11 \mathrm{~m} \mathrm{~s}^{-1}$ & & & \\
$b_{\text {low }}(\mu \mathrm{Pa})$ & $-0.2 \times 10^{4}$ & $0.2 \times 10^{4}$ & $-0.5 \times 10^{4}$ \\
$s_{\text {low }}\left(\mu \mathrm{Pa} \mathrm{m}{ }^{-1} \mathrm{~s}\right)$ & $0.4 \times 10^{4}$ & $0.3 \times 10^{4}$ & $0.4 \times 10^{4}$ \\
$R^{2}$ & 0.88 & 0.85 & 0.88 \\
For $U_{10}>9 \mathrm{~m} \mathrm{~s}^{-1}$ & & & \\
$b_{\text {high }}\left(\mathrm{m} \mathrm{s}^{-1}\right)$ & $-12.5 \times 10^{4}$ & $-4.4 \times 10^{4}$ & $-13.1 \times 10^{4}$ \\
$s_{\text {high }}\left(\mu \mathrm{Pa} \mathrm{m}^{-1} \mathrm{~s}\right)$ & $1.6 \times 10^{4}$ & $0.8 \times 10^{4}$ & $1.4 \times 10^{4}$ \\
$R^{2}$ & 0.95 & 0.96 & 0.97 \\
$U_{\lim }\left(\mathrm{m} \mathrm{s}^{-1}\right)$ & 10.4 & 10.3 & 11.7 \\
$p_{\lim }(\mu \mathrm{Pa})$ & $4.5 \times 10^{4}$ & $3.6 \times 10^{4}$ & $3.7 \times 10^{4}$ \\
\hline
\end{tabular}

coverage, and resilience to severe weather conditions. During this study, we were able to collect data without maintaining ship presence during several high wind speed events. Previous studies were mostly limited to wind speeds below $15 \mathrm{~m} \mathrm{~s}^{-1}$ (Table 2), so they were unable to successfully characterize higher wind speeds. The significant amount of high wind speed conditions encountered during this experiment allows us to propose a model extending the WOTAN technique measurement range to strong wind conditions, up to $21.5 \mathrm{~m} \mathrm{~s}^{-1}$. No evidence of an upper limit of our model, where the sound at $3 \mathrm{kHz}$ would be attenuated, has been found here. Further experiments are necessary to determine whether this critical wind speed exists. The positions of the meteorological buoys relative to the coast and the direction of the main winds limits the fetch to $100 \mathrm{~km}$ at the Lion buoy, and $50 \mathrm{~km}$ at the Azur buoy. This does not allow a fully developed sea at wind speed higher than 10 and $7 \mathrm{~m} \mathrm{~s}^{-1}$ at the sites Lion and Azur, respectively. Future experiments in the open ocean (e.g., Southern Ocean) will provide more data at high wind speed and with unlimited fetch, which will allow studying the impact of sea state on the wind noise and assessing the validity of our model at high wind speed.

The use of sound pressure level at $3 \mathrm{kHz}$ in this study was driven by the instrument self noise at $\sim 2 \mathrm{kHz}$ and the possible contamination by traffic noise at lower frequencies on one side, and the limitations observed for the high frequencies at high wind speeds on the other side. It is however not necessary to focus on this specific third octave band. Moreover, monitoring higher wind speed conditions than the ones presented here may necessitate the use of multiple frequencies. At high wind speeds, lower frequencies maintain a linear response to wind speed, while higher frequencies show decreasing amplitude/intensity/power with increasing wind speed. Further work is required to constrain the relation between higher frequencies and high wind speeds in relation to sea surface physical parameters (sea state, wave age, energy flux...). In the particular case of surface wind speed estimation, the use of $p_{3 \mathrm{kHz}}$ for wind speeds up to $25 \mathrm{~m} \mathrm{~s}^{-1}$, and $p_{500 \mathrm{~Hz}}$ for higher wind speeds, when wind-generated noise is loud enough to prevent masking by shipping noise, could be considered, allowing a wide wind speed range to be monitored.

This paper focuses on providing submesoscale measurements of surface wind speed combined with oceanographic profiles. We recorded $1 \mathrm{~min}$ every $10 \mathrm{~min}$, and considered the median of the acoustic measurements to provide a robust wind speed estimation for the duration of each glider profile-in this case measured every $2 \mathrm{~h}$ and $2 \mathrm{~km}$. This method allows the acquisition of high-resolution in situ forcing data, in weather conditions or locations of interest (e.g., storms, remote regions) for numerical models and satellite calibration (Schmidt et al. 2017). Recent progresses in the integration of PAM sensors into ocean gliders now enables continuous recording during a monthlong glider campaign (limited by the glider's battery). The variation of the listening area with the depth of measurement (Vagle et al. 1990) can be used to choose to measure wind speed over different spatial scales. For example, limiting the glider measurements to the upper 100-200 m would enable monitoring of a sea surface area of $0.1-0.5 \mathrm{~km}^{2}$, hence studying of smaller-scale processes than with typical 1000-m glider dives (e.g., land sea breezes, transient events). Continuous sampling throughout the glider dive, combined with sound speed and attenuation profiles measured by the glider, will allow better evaluation of the vertical distribution of ambient noise.

The combination of surface wind speed measurements with glider oceanographic profiles allows better observation and quantification of air-sea interaction processes, and monitoring of the associated processes in the ocean. Surface wind speed measurements allow correction of the bulk SST to obtain skin SST values, which are fundamental for the quantification of air-sea interaction processes (Alappattu et al. 2017). Heat and freshwater transport can be monitored from the air-sea interface to the water column, linking heat content changes in the ocean to meteorological events (Grist et al. 2016).

Wind noise is caused by complex physical processes, such as wave breaking and bubble inclusion (Wenz 1962), driven by weather, sea surface conditions, and history. As a first approximation, we estimate the instantaneous surface wind speed from measurement of wind noise. We believe that further experiments (e.g., glider campaigns together with surface processes monitoring) could improve the wind speed estimation, by 
accounting for more contributing parameters (wind duration, MABL stability, sea state, fetch...). Also, we could evaluate the ability to directly monitor physical parameters (whitecap coverage, bubble creation rate, airflow separation, spume drop production...) through analysis of ambient noise recorded by gliders. Such direct measurements would significantly improve the quantification of air-sea gas exchanges (Garbe et al. 2014), bubble-mediated carbon exchange (Monahan and Dam 2001), heat and moisture fluxes (Andreas et al. 2015), and sea salt aerosol production fluxes (Lewis and Schwartz 2004).

Onboard processing (e.g., TOL extraction, event detection) and real-time transmission of the data via Iridium connection will make it possible to detect targeted events (e.g., storm, rainfall) and trigger an adaptation of the sampling behavior to improve the observations. For example, fast and shallow dives during a storm or a rainfall event would increase the sampling resolution (Lee et al. 2012) of its effects on the water column (e.g., internal waves, mixing, freshwater input). The route of the glider can also be adapted to better sample a targeted event (e.g., along-track or cross-track sampling).

For future deployments, we suggest that in situ calibration of the PAM glider should be performed at the beginning of each deployment. Deploying the PAM glider at the surface from a small boat, next to a calibrated hydrophone, in various noise conditions (e.g., engine on/ off) should be sufficient to allow the acquisition of absolute sound levels. Also, the use of an integrated PAM sensor will reduce the interdeployment variability in the positioning of the sensor, and therefore allow use of the same in situ calibration for multiple deployments.

\section{Conclusions}

Surface wind speed can be measured remotely, derived from underwater acoustic measurements. The proposed two-regime linear model yields improved results in high wind speed conditions, extending the wind speed range to $2-21.5 \mathrm{~m} \mathrm{~s}^{-1}$.

The PAM sensor can be mounted on an ocean glider, diving from the surface to $1000 \mathrm{~m}$ deep, thus allowing the surface wind speed measurements to be combined with the oceanographic profiles (e.g., temperature, salinity). These PAM glider observations provide high-resolution, frequent, and localized in situ data for forcing numerical models and improving the understanding of the air-seaclimate system.

Acknowledgments. Support was provided by the French CNRS/NOISE project, the "Chantier Méditerranée" MISTRALS program (HyMeX component), the ANR
ASICSMED project (ANR 12-BS06-0003), and the MOOSE long-term observatory (SOERE/AllEnvi-SNO/ INSU). The authors acknowledge the staff of the French National Pool of Gliders (DT-INSU/CNRS-CETSM/ Ifremer) for the sustained glider deployments carried out in the framework of MOOSE, and the other deployments during the 2012-2013 DEWEX experiment. Support was also provided by the EU projects FP7 GROOM (Grant Agreement 284321) and the COST Action ES0904 "EGO" (Everyone's Gliding Observatories). The authors acknowledge Météo-France for supplying the meteorological buoy wind speed data, and Météo-France and the HyMeX program for supplying the model data, sponsored by Grants MISTRALS/HyMeX and the ANR-11-BS56-0005 IODA-MED project. This research was funded by the National Environmental Research Council (Grant NE/ N012070/1) and the Engineering and Physical Sciences Research Council, via the NEXUSS Centre of Doctoral Training in the Smart and Autonomous Observation of the Environment, and as part of the Cefas-UEA strategic alliance (Cefas Seedcorn SP002).

\section{REFERENCES}

Alappattu, D. P., Q. Wang, R. Yamaguchi, R. J. Lind, M. Reynolds, and A. J. Christman, 2017: Warm layer and cool skin corrections for bulk water temperature measurements for air-sea interaction studies. J. Geophys. Res. Oceans, 122, 6470-6481, https://doi.org/10.1002/2017JC012688.

Andreas, E. L, L. Mahrt, and D. Vickers, 2015: An improved bulk air-sea surface flux algorithm, including spray-mediated transfer. Quart. J. Roy. Meteor. Soc., 141, 642-654, https:// doi.org/10.1002/qj.2424.

Barclay, D. R., and M. J. Buckingham, 2013: Depth dependence of wind-driven, broadband ambient noise in the Philippine Sea. J. Acoust. Soc. Amer., 133, 62-71, https://doi.org/10.1121/ 1.4768885 .

Baumgartner, M. F., and D. M. Fratantoni, 2008: Diel periodicity in both sei whale vocalization rates and the vertical migration of their copepod prey observed from ocean gliders. Limnol. Oceanogr., 53, 2197-2209, https://doi.org/10.4319/lo.2008.53.5_part_2.2197.

, — , T. P. Hurst, M. W. Brown, T. V. N. Cole, S. M. Van Parijs, and M. Johnson, 2013: Real-time reporting of baleen whale passive acoustic detections from ocean gliders. J. Acoust. Soc. Amer., 134, 1814-1823, https://doi.org/10.1121/1.4816406.

Black, P. G., J. R. Proni, J. C. Wilkerson, and C. E. Samsury, 1997: Oceanic rainfall detection and classification in tropical and subtropical mesoscale convective systems using underwater acoustic methods. Mon. Wea. Rev., 125, 2014-2042, https://oi.org/ 10.1175/1520-0493(1997)125<2014:ORDACI >2.0.CO;2.

Bourassa, M., S. Gille, D. Jackson, J. B. Roberts, and G. Wick, 2010: Ocean winds and turbulent air-sea fluxes inferred from remote sensing. Oceanography, 23, 36-51, https://doi.org/ 10.5670/oceanog.2010.04.

Burgess, W. C., 2010: Development of a wideband acoustic recording tag to assess the acoustic behaviour of marine wildlife. Final Rep., Greeneridge Sciences, Inc. Tech. Rep. GS0118A-1001, 26 pp., http://www.dtic.mil/get-tr-doc/pdf?AD=ADA513321. 
Callaghan, A., G. De Leeuw, L. Cohen, and C. D. O'Dowd, 2008: Relationship of oceanic whitecap coverage to wind speed and wind history. Geophys. Res. Lett., 35, L23609, https://doi.org/ 10.1029/2008GL036165.

Carey, W. M., J. W. Fitzgerald, E. C. Monahan, and Q. Wang, 1993: Measurement of the sound produced by a tipping trough with fresh and salt water. J. Acoust. Soc. Amer., 93, 3178-3192, https://doi.org/10.1121/1.405702.

Cazau, D., J. Bonnel, J. Jouma'a, Y. le Bras, and C. Guinet, 2017: Measuring the marine soundscape of the Indian Ocean with southern elephant seals used as acoustic gliders of opportunity. J. Atmos. Oceanic Technol., 34, 207-223, https://doi.org/ 10.1175/JTECH-D-16-0124.1.

Crouch, W. W., and P. J. Burt, 1972: The logarithmic dependence of surface-generated ambient-sea-noise spectrum level on wind speed. J. Acoust. Soc. Amer., 51, 1066, https://doi.org/ 10.1121/1.1912926.

Dos Santos, F. A., P. M. São Thiago, A. L. S. de Oliveira, R. Barmak, J. A. M. Lima, F. G. de Almeida, and T. P. Paula, 2016: Investigating flow noise on underwater gliders acoustic data. J. Acoust. Soc. Amer., 140, 3409-3409, https://doi.org/ 10.1121/1.4970954.

Erbe, C., A. Verma, R. McCauley, A. Gavrilov, and I. Parnum, 2015: The marine soundscape of the Perth Canyon. Prog. Oceanogr., 137, 38-51, https://doi.org/10.1016/j.pocean.2015.05.015.

Farmer, D. M., and D. D. Lemon, 1984: The influence of bubbles on ambient noise in the ocean at high wind speeds. J. Phys. Oceanogr., 14, 1762-1778, https://doi.org/10.1175/1520-0485(1984) 014<1762:TIOBOA $>2.0$. CO;2.

Foreman, R. J., and S. Emeis, 2010: Revisiting the definition of the drag coefficient in the marine atmospheric boundary layer. J. Phys. Oceanogr., 40, 2325-2332, https://doi.org/10.1175/ 2010JPO4420.1.

Garbe, C. S., and Coauthors, 2014: Transfer across the air-sea interface. Ocean-Atmosphere Interactions of Gases and Particles, P. S. Liss and M. T. Johnson, Eds., Springer Earth System Sciences, Springer, 55-112, https://doi.org/10.1007/978-3-642-25643-1_2.

Grist, J. P., S. A. Josey, Z. L. Jacobs, R. Marsh, B. Sinha, and E. Van Sebille, 2016: Extreme air-sea interaction over the North Atlantic subpolar gyre during the winter of 2013-2014 and its sub-surface legacy. Climate Dyn., 46, 4027-4045, https://doi.org/10.1007/s00382-015-2819-3.

Kent, E. C., 1998: A comparison of ship- and scatterometer-derived wind speed data in open ocean and coastal areas. Int. J. Remote Sens., 19, 3361-3381, https://doi.org/10.1080/ 014311698214046.

Klinck, H., and Coauthors, 2012: Correction: Near-real-time acoustic monitoring of beaked whales and other cetaceans using a Seaglider. PLoS ONE, 7 (8), https://doi.org/10.1371/ annotation/57ad0b82-87c4-472d-b90b-b9c6f84947f8.

Large, W. G., and S. Pond, 1981: Open ocean momentum flux measurements in moderate to strong winds. J. Phys. Oceanogr., 11, 324-336, https://doi.org/10.1175/1520-0485(1981)011<0324: OOMFMI>2.0.CO;2.

Lee, C., J. Gobat, and L. Rainville, 2012: An autonomous investigation of Kuroshio and mesoscale impacts on upper ocean response to typhoon forcing. University of Washington Applied Physics Laboratory Publ., 11 pp.

Lemon, D. D., D. M. Farmer, and D. R. Watts, 1984: Acoustic measurements of wind speed and precipitation over a continental shelf. J. Geophys. Res., 89, 3462-3472, https://doi.org/10.1029/ JC089iC03p03462.

Lewis, E. R., and S. E. Schwartz, 2004: Sea Salt Aerosol Production: Mechanisms, Methods, Measurements, and Models. Geophys.
Monogr., Vol. 152, Amer. Geophys. Union, 413 pp., https:// doi.org/10.1029/GM152.

Merchant, N. D., K. M. Fristrup, M. P. Johnson, P. L. Tyack, M. J. Witt, P. Blondel, and S. E. Parks, 2015: Measuring acoustic habitats. Methods Ecol. Evol., 6, 257-265, https://doi.org/ 10.1111/2041-210X.12330.

Moat, B. I., M. J. Yelland, R. W. Pascal, and A. F. Molland, 2005: An overview of the airflow distortion at anemometer sites on ships. Int. J. Climatol., 25, 997-1006, https://doi.org/10.1002/joc.1177.

Monahan, E. C., and I. G. O'Muircheartaigh, 1986: Whitecaps and the passive remote sensing of the ocean surface. Int. J. Remote Sens., 7, 627-642, https://doi.org/10.1080/01431168608954716. _ and H. G. Dam, 2001: Bubbles: An estimate of their role in the global oceanic flux of carbon. J. Geophys. Res., 106, 93779383, https://doi.org/10.1029/2000JC000295.

_ C. W. Fairall, K. L. Davidson, and P. J. Boyle, 1983: Observed inter-relations between $10 \mathrm{~m}$ winds, ocean whitecaps and marine aerosols. Quart. J. Roy. Meteor. Soc., 109, 379-392, https:// doi.org/10.1002/qj.49710946010.

_ A. Staniec, and P. Vlahos, 2017: Spume drops: Their potential role in air-sea gas exchange. J. Geophys. Res. Oceans, 122, 9500-9517, https://doi.org/10.1002/2017JC013293.

Moore, S. E., B. M. Howe, K. M. Stafford, and M. L. Boyd, 2007: Including whale call detection in standard ocean measurements: Application of acoustic seagliders. Mar. Technol. Soc. J., 41, 53-57, https://doi.org/10.4031/002533207787442033.

Nott, B. J., 2015: Long-endurance maritime surveillance with ocean glider networks. M.S. thesis, Dept. of Oceanography, Naval Postgraduate School, 87 pp.

Nuret, M., and N. Fourrié, 2011: AROME_WMED. GAME/ CNRM, Météo-France, accessed 19 February 2015, https:// doi.org/10.6096/hymex.arome_wmed.2012.02.20.

Nystuen, J. A., and B. Ma, 2002: Using ambient sound to passively monitor sea surface processes. Proceedings of the Sixth Pan Ocean Remote Sensing Conference (PORSEC), B. P. Pasaribu et al., Eds., PORSEC Association, 9-14.

Piggott, C. L., 1964: Ambient sea noise at low frequencies in shallow water of the Scotian shelf. J. Acoust. Soc. Amer., 36, 2152-2163, https://doi.org/10.1121/1.1919337.

Rainaud, R., and Coauthors, 2016: Characterization of air-sea exchanges over the Western Mediterranean Sea during HyMeX SOP1 using the AROME-WMED model. Quart. J. Roy. Meteor. Soc., 142, 173-187, https://doi.org/10.1002/qj.2480.

Riser, S. C., J. Nystuen, and A. Rogers, 2008: Monsoon effects in the Bay of Bengal inferred from profiling float-based measurements of wind speed and rainfall. Limnol. Oceanogr., $\mathbf{5 3}$ 2080-2093, https://doi.org/10.4319/lo.2008.53.5_part_2.2080.

Rudnick, D. L., 2016: Ocean research enabled by underwater gliders. Annu. Rev. Mar. Sci., 8, 519-541, https://doi.org/ 10.1146/annurev-marine-122414-033913.

Schmidt, K. M., S. Swart, C. Reason, and S. Nicholson, 2017: Evaluation of satellite and reanalysis wind products with in situ Wave Glider wind observations in the Southern Ocean. J. Atmos. Ocean. Technol., 34, 2551-2568, https://doi.org/ 10.1175/JTECH-D-17-0079.1.

Shaw, P. T., D. R. Watts, and H. T. Rossby, 1978: On the estimation of oceanic wind speed and stress from ambient noise measurements. Deep-Sea Res., 25, 1225-1233, https://doi.org/10.1016/ 0146-6291(78)90015-2.

Testor, P., and Coauthors, 2010: Gliders as a component of future observing systems. Proceedings of OceanObs'09: Sustained Ocean Observations and Information for Society, J. Hall, D. E. Harrison, and D. Stammer, Eds., Vol. 2, ESA Publ. WPP306, 961-978. https://doi.org/10.5270/OceanObs09.cwp.89. 
_, and Coauthors, 2017: Multi-scale observations of deep convection in the northwestern Mediterranean Sea during winter 2012-2013 using multiple platforms. J. Geophys. Res. Oceans, 123, 1745-1776, https://doi.org/10.1002/2016JC012671.

Urick, R., and W. A. Kuperman, 1989: Ambient noise in the sea J. Acoust. Soc. Amer., 86, 1626, https://doi.org/10.1121/1.398683.

Vagle, S., W. G. Large, and D. M. Farmer, 1990: An evaluation of the WOTAN technique of inferring oceanic winds from underwater ambient sound. J. Atmos. Oceanic Technol., 7, 576-595, https:// doi.org/10.1175/1520-0426(1990)007<0576:AEOTWT>2.0.CO;2.

Vakkayil, R., H. C. Graber, and W. G. Large, 1996. Oceanic winds estimated from underwater ambient noise observations in SWADE. Oceans'96 MTS/IEEE Conference Proceedings; The Coastal Ocean-Prospects for the 21st Century, Vol. 1, IEEE 45-51. https://doi.org/10.1109/oceans.1996.572450.

Wanninkhof, R., 2014: Relationship between wind speed and gas exchange over the ocean revisited. Limnol. Oceanogr. Methods, 12,351-362, https://doi.org/10.4319/lom.2014.12.351.
Watts, D. G., and D. W. Bacon, 1974: Using a hyperbola as a transition model to fit two-regime straight-line data. Technometrics, 16, 369373, https://doi.org/10.1080/00401706.1974.10489205.

Weller, R. A., E. F. Bradley, J. B. Edson, C. W. Fairall, I. Brooks, M. J. Yelland, and R. W. Pascal, 2008: Sensors for physical fluxes at the sea surface: Energy, heat, water, salt. Ocean Sci., 4, 247-263, https://doi.org/10.5194/os-4-247-2008.

Wenz, G. M., 1962: Acoustic ambient noise in the ocean: Spectra and sources. J. Acoust. Soc. Amer., 34, 1936-1956, https://doi.org/ 10.1121/1.1909155.

Wiggins, S. M., 2013: Acousonde: Acoustic Tag Calibration at the Transducer Evaluation Center (TRANSDEC). Scripps Institution of Oceanography, University of California, San Diego, Marine Physical Laboratory Tech. Memo. TM-543, 28 pp.

Zhang, H.-M., J. J. Bates, and R. W. Reynolds, 2006: Assessment of composite global sampling: Sea surface wind speed. Geophys. Res. Lett., 33, L17714, https://doi.org/10.1029/ 2006 GL027086. 